\title{
TRAJETÓRIA DA MULHER EM DIREÇAO À ESTERILIZAÇÃO CIRÚRGICA FEMININA: UM ESTUDO FENOMENOLÓGICO*
}

\author{
WOMEN'S PROGRESS TOWARDS SURGICAL TUBAL \\ STERILIZATION A PHENOMENOLOGICAL STUDY
}

Clarice Marcolino ${ }^{1}$

Néia Schor ${ }^{2}$

MARCOLINO, C.; SCHOR, N. Trajetória da Mulher em Direção à Esterilização Cirúrgica Feminina: Um Estudo Fenomenológico, Rev. Bras. Cresc. Desenv. Hum., São Paulo, 5 (1/2), 1995.

Resumo: Este estudo nasceu de uma preocupação, como enfermeiras e docentes de enfermagem, com as mulheres que vivenciam a escolha do método contraceptivo definitivo - a esterilização cirúrgica feminina. Dessa forma, nossa tryetória neste trabalho consiste na busca de compreensão da vivência das mulheres no processo de escolha desse método contraceptivo. Para essa finalidade, utilizamos a pesquisa qualitativa - enfoque fenomenológico. Esta estratégia possibilitou-nos apreender a essência do fenómeno sem, no -ntanto, prender-nos a fatores determinantes do mesmo. Como forma de desvelar o fenómeno, utilizamos uma pergunta orientadora, que norteou as descrições dos sujeitos sociais: 'Taie para mim sobre a sua experiência com os jeitos de evitar filhos.” Foram colhidos 22 depoimentos, os quais, através de uma análise fenomenológica, evidenciaram seis diferentes temas: a convivência com os métodos contraceptivos temporários; o sentido da esterilização cirúrgica; a participação masculina na contracepção; o seu ser mãe; a condição socioeconômica; o número de filhos e o seu horizonte existencial em face da esterilização. Essa abordagem compreensiva possibilita, pelos seus resultados, abrir novos horizontes na assistência às mulheres que buscam meios para controlar a sua fecundidade.

Palavras-chave: esterilização cirúrgica feminina, contracepção cirúrgica feminina, fenomenologia, saúde da mulher, planejamento familiar, método contraceptivo cirúrgico, mulheres.

Summary: This study grew from a concern of the authors-nurses and teachers of nursing-for women who face the choice of the definitivo contraceptiva method - the women's surgical sterilization. Therefore, the I route chosen in this work was to try to comprehend the living experience of these women in the process of choosing this contraceptive method. For this we used qualitative research - the phenomenologica approach. This theoretical metbodologcal strategv made it possible for us to grasp the essence of th phenomenon, without, howe er, limiting ourselves to determining factors. As a means to unrave $\wedge S^{\prime}$ th $\sim$ phenomenon, a guiding question was asked to guide $\wedge$ the descript $\sim$ ons of the socia subjects: "'Ta k to $\mathrm{m} \sim$ about your experience of ways of avoiding children. "Twenty-two statements were taken, which, through phenomenological analysis, revealed six different themes: the contact with temporary contraceptive methods, the meaning of surgical sterilization, male participation in contraception, being a mother, the social and economic condition, the number of children and women's existential outlook when facing sterilization. This comprehensive approach, through its results, opens new horizons to the care of women who seek means of controlling their fertility.

Key-words: women's surgical sterilization; women’s surgical contraception, phenomenology, women's health, family planning, surgical contraceptive method, women.

* Dissertação apresentada ao curso de mestrado da Faculdade da Saúde Pública da USP em 1995, cujo título foi: Esterilização Cirúrgica feminina: um estudo fenomenológico.

1 Enfermeira docente da Escola de Enfermagem da Universidade Federal de Minas Gerais. End.: Av. Bernardo Vasconcelos, 2350/703 Belo Horizonte - MG. CEP 31160-440.

2 Profa. Assoc. do Departamento de Saúde Materno Infamtil da Faculdade de Saúde Pública da Universidade de São Paulo. End: Av Dr. Arnaldo, 715. São Paulo - SP. CEP 01246-904 - Tel.: (011) 3061-5233 R. 2203 


\section{INTRODUÇÃO}

Os debates em torno do planejamento familiar sempre se mostraram a nós de forma polarizada: controle da natalidade ou planejamento familiar? Apesar dessa controvérsia sempre tivemos como princípio ser favoráveis, não a uma anticoncepção coercitiva, mas àquela que se fundamentasse no exercício de escolha da mulher.

O planejamento familiar é um aspecto da assistência que nos atrai, talvez pela vontade e disposição em ajudar as mulheres que, em muitos momentos, recorrem desesperadamente a soluções não refletidas para evitar o nascimento de filhos não desejados. Muitas delas recorrem ao aborto em precárias condições e na clandestinidade. Observamos, também, que essas mulheres são muito solitárias nessa decisão, principalmente as de baixo nivel socioeconômico.

Muito embora essa situação venha se apresentando a nós permeada por ambiguidades, nosso trabalho sempre se pautou na busca de compreender a condição dessas mulheres, que muito nos sensibiliza.

Nossa experiência em planejamento familiar, na cidade de Belo Horizonte, com a clientela feminina pobre, tem mostrado que a esterilização cirúrgica tem sido o método ao qual recorre grande parte das mulheres. Quando estas procuram os serviços de saúde, vêm com a decisão tomada pelo método definitivo e, muito raramente, revêem essa decisão.

Consideramos, no entanto, que a esterilização cirúrgica feminina ${ }^{3}$ como um método de controle da fecundidade, deveria ser utilizado somente em casos excepcionais; percebemos porém, na prática, uma tendência das mulheres em utilizar esse método cirúrgico, o que começou a chamar nossa atenção. Muitas delas dizem que gostariam de submeter-se a essa cirurgia, mas sabem que não estão dentro dos critérios estabelecidos pelos serviços de saúde para que sua laqueadura seja aprovada ou, não podem, particularrnente, custear as despesas desse tipo de intervenção.

Em geral, os serviços públicos de saúde estabelecem normas para a aprovação de esterilização cirúrgica, baseadas em critérios de risco gestacional. Esses critérios são tanto de natureza social quanto biológica, como por exemplo: número de filhos, idade e paridade da mulher, além de determinados problemas de saúde e número de partos operatórios, dentre outros.
As mulheres chegam ao centro de saúde quase implorando pela ligação de trompas e lamentando as dificuldades em conseguí-la face aos critérios que os serviços estabelecem. A medida que interagíamos com essas mulheres, fomos percebendo, gradativamente, que a forma como nós, os profissionais dos serviços de saúde, as assistimos, não as contemplavam no seu mundo cotidiano, no seu existir. Começamos, então a visualizar uma possibilidade e ir além da nossa compreensão atual e trabalhar numa perspectiva mais humana e integralizadora.

Ao decidir pela esterilização cirúrgica, a mulher atribui significados à mesma, que para nós estão ocultos. Desvelar esse conjunto de elementos presentes no processo de decisão pela ligadura de trompas é a nossa intenção neste estudo. Buscamos, assim, contribuir para ampliar nossos horizontes, enquanto profissinais de saúde, no assistir à essa clientela.

Neste processo de decisão pela esterilização cirúrgica, é possível buscar o para que $a$ intenção a que essa decisão responde. O que pretendemos desnudar é como a esterilização se mostra àquela que experimenta a decisão de recorrer a essa prática contraceptiva.

As mulheres pobres que decidem se submeter à esterilização têm acesso a serviços públicos ou filantrópicos para realizar esse tipo de cirurgia. Vários são os momentos de um longo percurso.

Em geral, o trabalho que os serviços de planejamento familiar desenvolvem é, na maioria das vezes, de natureza multiprofissional envolvendo a participação de profissionais de saúde de várias especialidades, com médico ginecologista, assistente social, enfermeiro e psicólogo.

Observamos que as nossas ações para essa atividade de planejamento familiar, desconsideram, na maioria das vezes, a vivência das mulheres. Daí a idéia de realizar um estudo no qual fosse possível assumir o olhar daquelas que vivenciam o processo de decidir pela esterilização cirúrgica, abrir daí uma janela, compor um terceiro olhar, na tentativa de compreender como a esterilização cirúrgica mostra-se para aquelas que a ela irão se submeter.

Na leitura específica, percebemos uma lacuna nessa perspectiva de abordagem. Encontramos o lado profissional e técnico-científico. A literatura consultada aborda a temática do controle da reprodução em vários aspectos, configurando-

3 A esterilzação cirúrgica feminina, também conhecida como laqueadura tubária ou ligadura de trompas. consiste na interrupção da continuidade das trompas de Falópio, por oclusão ou seccão. Embora cirurgias de reversibilidade venham ocorrendo, é considerada ainda como método irreversível, definitivo, porque elimina a possibilidade de procriação futura. 
se num contexto demográfico, econômico e social, onde o dimensionamento da prole emerge de maneira controvertida: planejamento familiar ou controle da natalidade.

A ausência de uma posição governamental explícita sobre o controle da reprodução tem gerado conflitos e ambiguidades na nossa prática contraceptiva, particularmente para a esterilização cirúrgica.

À medida que os números revelam a grande procura pela esterilização, permanecem ocultas outras facetas que pretendemos tentar desvelar, com a co-participação daquelas que vivenciam em seu espaço de vida o fenômeno de decidir pela esterilização cirúrgica. Merleau-Ponty nos clareia essa situação dizendo que: "a generalidade e a probabilidade não são ficções, mas fenômenos, e devemos pois encontrar no pensamento estatístico um fundamento fenomenológico. Ela pertence necessariamente a um ser que está fixo, situado e investido no mundo" (MEMERLEAU-PONTY, 1971).

É neste sentido que intencionamos com esse estudo interpretar os significados dos atos e fenômenos que permeiam essa decisão, na busca de novos caminhos para uma questão complexa e polêmica. Para desnudá-los percorreremos o caminho guiado pela fenomenologia, sabendo de antemão que a desocultação total não é possível, por isso a pesquisa sempre prossegue.

\section{REFERENCIAL TEÓRICO-METODOLÓGICO}

Segundo MARTINS \& BICUDO (1983), a fenomenologia procura abordar o fenômeno, aquilo que se manifesta de si mesmo, de modo que não o parcializa ou explica a partir de conceitos prévios, de crenças ou afirmações, enfim, de um referencial teórico que o aprisiona; mas ela tem a intenção de abordá-lo diretamente, interrogando-o tentando descrevê-lo e procurando captar a sua essência.

A fenomenologia preocupa-se com a essência do fenômeno e a sua investigação é um interrogar a coisa mesma. Fenômeno é entendido como aquilo que surge para a consciência como resultado de uma interrogação. Etmologicamente, o termo procede do grego - phainomenon e significa discurso esclarecedor a respeito daquilo que se mostra para o sujeito interrogador, origina-se do verbo phainestai, que significa trazer à luz, no sentido de desvelar. Fenômeno é, então, tudo o que se mostra, portanto, manifesta-se, desvela-se ao sujeito que o interroga.

A essência do fenômeno pode mostrar-se nos discursos dos sujeitos. Assim a compreensão do processo de decisão pela esterilização cirúrgica só pode ser concretizada se nós voltarmos para a mulher, procurando através das descrições ${ }^{4}, o$ seu ver e perceber esse processo de decisão.

Através de seu logus, de sua fala, é possível chegar ao significado dessa experiência, na medida em que a fala revela parte do ser do homem. Assim é necessário buscar a fala daquelas que vivenciam o processo de decidir pela esterilização cirúrgica, pois, é somente quem vivência o processo que pode tornar manifesto aquilo que foi fundamental para ela como sujeito dessa experiência.

Após colhidas as descrições o pesquisador tem por tarefa descrever o fenômeno tal como se apresenta na ordem vivida de um determinado grupo ou classe social. Para CAPALBO (1984), quando o pesquisador está diante dos dados, para os quais não há categorias prontas, pré-determinadas, a formulação das categorias far-se-á à luz dos dados brutos visando a classificá-los. Obtém-se, dessa forma, categorias concretas e não abstratas.

A observação, ou percepção qualitativa dos dados, busca separar o que é contingente daquilo que é essencial e que se mostra no próprio dado oferecendo-nos, porém, uma percepção não concluída ou em perspectivas. A categoria concreta surge da situação em que é observada. Parte-se daquilo que é vivido, relatado pelos sujeitos que consideram, em sua vivência, o que é, para eles, determinado fenômeno. Nesse trabalho de classificação, realiza-se um esforço para se compreender o significado das informações obtidas pela análise descritiva, mediante a qual vai-se percebendo o tipo e a qualidade da informação, chegase a uma percepção mais clara, direta, intuitiva do fenômeno; tem-se o insigh dos aspectos mais significativos da situação, tal como ela se mostra para os pesquisadores e pesquisados.

A investigação fenomenológica não terá um problema, mas sim, uma interrogação. Para MARTINS \& BICUDO (1989), quando o pesquisador interroga, ele terá uma trajetória, estará caminhando em direção ao fenômeno, naquilo que se manifesta por si, através do sujeito que experimenta a situação. Ao interrogar, ele estará focalizando o fenômeno e não o fato. Ele não terá qualquer definição a priori, e isso não significa que ele não tenha um pensar sobre o fenômeno. Ao interrogar, ele tem um pré-reflexivo. O nosso pré-

4 Segundo MARTINS \& BICUDO (1983) a descnção coloca em evidência a expetiência consciente de um indivíduo em detenninado campo do conhecimento. 
reflexivo é o nosso pensar, construído na nossa vivência.

\section{O REVELAR DAS FALAS}

A interpretação das falas permitiu-nos observar convergências entre os conteúdos. Essas convergências possibilitaram-nos o desvelamento do processo de decisão pela esterilização cirúrgica. Desse ato compreensivo, pudemos apreender facetas referentes à existência da mulher como ser que vivencia o processo de decidir pelo método contraceptivo definitivo. Assim, as convergências dos discursos permitiram-nos a elaboração das categorias reveladoras da essência do fenômeno.

\section{Convivência com os métodos contraceptivos temporários}

A interpretação da prática anticoncepcional, no cotidiano de busca das mulheres, apresenta importantes significados no processo de decidir pela esterilização cirúrgica. Neste, a experiência com os métodos contraceptivos temporários desempenha papel significativo. As falas das mulheres apontam para duas facetas relevantes: para a do esgotamento das possibilidades com os métodos temporários e para a do confronto desses com o método definitivo - a esterilização cirúrgica. Foi-nos possível apreender quais métodos usam e como usam.

A pílula é o método temporário mais conhecido e usado. Ocorre, no entanto, o abandono de seu uso, associado a três principais motivos: problemas de saúde que contra-indicam a sua continuidade, efeitos colaterais e falhas. Podemos conferir esses aspectos nos fragmentos dos discursos: “(...) fiquei 10 anos tomano ele? né. Depois começei a lê poblema de pressão... ai o médico falô comigo: é melhor a senhora pará porque já tem muito tempo. tá teno poblema de pressão, eu aconselho a senhora pará agora, não toma mais a pílula".

“(...) eu já tomei anticoncepcional, já experimentei vários e não dei certo, todos eu passo mal, me dá vômitos, dor de cabeça”.

"(...) falei assim: se a gente bobeá no resguardo, é perigoso apanhá depois que passa, né, porque eu acho que o outro foi assim, assim que terminô, eu achei que o comprimido deu certo e não deu, eu fiquei grávida logo depois, antes da menina inteirá um ano e meio ... porque ele (o médico) teimava comigo: a senhora não tomou o remédio direito, mas eu tomava. mais parecia que o comprimido não valia, sabe... não adiantava não... porque do outro eu tomei a cartela toda... quando eu fui ver... foi logo depois do resguardo".

Muitas mulheres fazem o confronto do uso da pílula com problemas de saúde, efeitos colaterais e falhas; apontando a esterilização como uma saida para a contracepção. Vejamo recortes de discursos:

“(...) e fiquei tomano comprimido, mesmo tomano comprimido eu engravidei, ai que eu quero ligá mesmo á..) se eu continuá tomano a pílula eu tenho medo de engravidá".

“(...) comprimido eu não me dou muito com comprimido não, igual esse que eu tô tomano, Tá me dano enjoô, igual eu fico nervosa e tudo ... então o único jeito é só; a ligadura mesmo."

Analisando o mais conhecido e citado meio contraceptivo, a pílula, várias falas revelan a insegurança em relação aos efeitos colaterais que provocam, aos problemas de saúde que contra indicam seu uso e as falhas, muitas vezes decorrentes da maneira como usam. A difícil convivencia com a pílula, verbalizada pelas mulheres, possibilitou-nos entender como a ação diária da contracepção é uma experiência dificil para a mulher levando-a ao abandono da mesma, partindo para a esterilização cirúrgica.

O dispositivo intra-uterino (DIU) é outro método mencionado e usado pelas mulheres, porém pudemos captar sua pouca aceitabilidade entre elas, bem como a menção das complicações clínicas geradas pelo seu uso.

O uso do método da tabela revelou dificuldades no seu monitoramento, resultando em falhas, fato que desestimula as mulheres em continuar a usá-lo. A tabela é um método, cuja eficácia está associada ao conhecimento do período fértil e à cooperação do homem e da mulher. $\mathrm{O}$ fato de as mulheres não conhecerem bem o funcionamento do método e o de desconhecerem a fisiologia do seu corpo somam-se, levando-as a não confiar na eficácia de sua ação contraceptiva. Observemos a seguinte unidade de significado:

“(...) aí, o médico me ensinô tabela; eu fiquei fazeno tabela; aí quando minha menina tava com 2 anos, eu fui e engravidei de novo".

O preservativo e a vasectomia são dois métodos de regulação da fecundidade que solicitam a participação do homem. Foi possível, não obstante, a ausência de sua própria fala, apreender a recusa do companheiro em colaborar no processo de contracepção. O condom é um acessório que os incomoda, e em muitas situações eles as- 
sumem atitudes opressoras e de ameaça. Percebemos a hostilidade com que as mulheres são tratadas na convivência com seus companheiros. Pudemos apreender em suas falas, gostos e em expressões outras de suas emoções, a dificuldade que as mulheres têm em manifestar suas necessidades. Sentem-se constrangidos frente a negativa de colaboração de seus companheiros e revelam, com certa tristeza, a carência de sua solidariedade. O recorte de discurso que se segue é um exemplo que indica esse entendimento, vejamos:

“(...) aí ela falou que ia receitar camisinha pro meu marido e aí eu falei assim: não adianta nem receitá porque ele não usa. Eu fui franca com ela, porque assim né, se ele usasse, tinha evitado mais uns tempo prá mim num arrumá, porque a médica avisô prá mim, que as minha gravidez são de alto risco. Eu cheguei falei né; ele falou: se for prá usa camisinha acabo".

Os dados da Sociedade Civil Bem-Estar Familiar - BEMFAM (1986) - mostram que no Brasil, como um todo 2/3 das mulheres de 15 a 44 anos em união consensual, usam algum método anticoncepcional, concentrando-se em dois métodos: a pílula e a esterilização. O peso desses dois métodos nas alternativas contraceptivas, denota a precariedade de opções para a mulher brasileira.

SERRUYA (1992) coloca-nos que o desconhecimento dos métodos é a principal fonte de conflito na ação contraceptiva e vai muito além da falta de acesso às informações claras e linguagem acessível. Esse desconhecimento é mais profundo e tem origem na relação com o corpo, onde a concreção das vivências corporais parece ponto de partida para entendermos o porquê para a mulher é tão difícil conviver com seu próprio corpo.

No caso específico da esterilização cirúrgica feminina foi possível percebermos que as mulheres submetem-se a ela, em grande parte por não terem domínio sobre seus corpos.

Para MERLEAU-PONTY (1971), o corpo exprime a existência; é a nossa maneira de nos comunicarmos com o mundo. Nosso corpo é nosso veículo do ser no mundo. Não poderíamos apreender as coisas desse mundo sem a mediação da nossa experiência corporal. Ele é nosso ponto de vista sobre o mundo.

A percepção do corpo segundo a concepção de Merleau-Ponty permite-nos compreender como a mulher coloca-se no mundo mediada pelo seu corpo deixando emergir a possibilidade de transcender de uma situação, para outra situação. Pelo esquema corporal, o corpo aparece para nós como posição em vista de uma certa tarefa atual ou possível e é evidentemente na ação que a especialidade do corpo se completa.

Merleau-Ponty descreve o comportamento dos homens como dialético, no sentido do ultrapassamento. A dialética é a tensão de uma existência em direção à outra existência. Essa tensão permite o movimento de transcendência.

A trajetória percorrida pela mulher que experimenta a busca por um método contraceptivo temporário, possibilita-nos compreender que ela possa até optar pela laqueadura, por um processo de esgotamento de possibilidades com esses métodos. O cotejamento destes com a esterilização cirúrgica, leva a mulher à uma situação tensional, desencadeando a passagem para um método mais radical - a esterilização cirúrgica. Nesse momento de transcendência, em que a mulher é levada a submeter-se à esterilização cirúrgica, ela atribui à esta determinados significados.

\section{O sentido da esterilização cirúrgica}

Os discursos apontam para a esterilização como um método de difícil acessibilidade. É longa e árdua a tarefa de peregrinação das mulheres pelas várias instituições até obterem permissão para fazer a ligadura de trompas. Nesse processo de busca o caminho é penoso. Além do drama de seu dia-a-dia as mulheres passam por várias entrevistas com profissionais de saúde de diferentes especialidades, enfrentam os critérios institucionais, nos quais devem estar enquadradas. A unidade de significado que se segue é um exemplo que mostra essa perspectiva de compreensão.

“ (...) eu já sofri tanto batalhando prá podê ligá ... pagá eu num posso pagá. né ... eu consegui agora né, com Dr. X. É, aí já mandô as meninas iniciá os papel prá mim (...) eu vô fazê pelo SUS"

Outro aspecto captado nas falas revela um desejo enraizado em fazer a ligadura de trompas, a disposição em fazer tal cirurgia parece não ser recente. Vejamos fragmentos de depoimentos que revelam essa faceta:

“(...) a idéia de ligá eu achei muito boa. Há muitos anos que eu queria fazê isso, mas nunca tive oportunidade de fazê, agora eu tô decidida ... agora vô enfrente”.

“(...) faz muito tempo que eu já vinha tentano, mas não consegui, desde quatro filhos ... ai o poblema foi esse mesmo”.

Sobre a decisão pela ligadura de trompas, podemos recorrer à Merleau-Ponty para melhor compreendermos essa faceta de tantas ambigüidades. Para o filósofo, o homem, ser em situação, não é totalmente livre, ele já está comprometido com o seu envolvimento com o mundo, sua esco- 
lha dá-se em meio no qual não há um total poder de controle, não sendo, portanto, completamente consciente: "nascer é ao mesmo tempo nascer do mundo e nascer no mundo. O mundo já está constituído, mas também nunca completamente constituído. Sob a primeira relação somos solicitados, sob a segunda somos abertos a uma infinidade de possíveis.” (MERLEAU-PONTY, 1971).

Não há, portanto, nem determinismos absolutos, nem escolha absoluta e "eu dou um sentido e um futuro à minha vida, que saem do meu presente e do meu passado e, em particular do meu modo de coexistência".

A mulher não decide por ela mesma - escolha absoluta - nem há determinismos externos. Não há esses pólos, mas a escolha dá-se por inteiro, da maneira de estar no mundo.

As mulheres compreendem a esterilização como um meio mais seguro e mais eficaz para limitar o número de filhos. A cirurgia passa a ser vista como uma solução para vários problemas, na expectativa mais íntima das mulheres.

A esterilização cirúrgica tem o sentido de ser o recurso definitivo, eliminando a insegurança de uma gestação indesejada e a necessidade de não preocupar-se com a contracepção no seu dia-a-dia.

Em face às dificuldades de fazer uma contracepção cotidiana, solitária, sem a colaboração do homem, o definitivo tem o sentido de encerrar a vida reprodutiva, e não a sexual, através de um método radical, no qual a sua responsabilidade em termos reprodutivos é quase inexistente.

Outra faceta apreendida dos discursos é a compreensão da esterilização como um método em que pesam os critérios de risco obstétrico estatístico. As mulheres entendem que há critérios institucionais que são estabelecidos para que a ligadura de trompas seja aprovada. Alguns desses critérios já foram assimilados no discurso das mulheres como o números de filhos, a idade e problemas de saúde.

A esterilização é um recurso último e dramático que as mulheres utilizam como uma reação às pressões exercidas sobre elas. Essas pressões são numerosas e desgastantes tais como: dificuldade de acesso aos métodos contraceptivos, falta de colaboração do companheiro, falta de conhecimento do corpo, conflitos existenciais, excesso de trabalho. Frente a essas pressões, elas reagem procurando o recurso definitivo para livrarem-se da condição biológica e social de procriadoras. A ilusão de uma solução fácil para problemas e sentimentos latentes presentes, mas sobre os quais elas não têm controle, levam-nas a mutilarem seus corpos e seu espírito para fazerem frente às perspectivas de vida que se lhes oferecem.

\section{A participação masculina na contracepção}

A convergência das falas que sinalizam essa categoria foi explicitada com maior ênfase na participação do homem na contracepção. Um outro aspecto de igual importância, revelado nos discursos, é a idéia de que os homens partilhem da vivência de criar os filhos.

A concepção é o resultado natural do intercurso sexual entre um homem e uma mulher; partindo dessa premissa, espera-se que a contracepção seja um fenômeno também, por natureza, resultante da conjugação de esforços dos parceiros igualmente implicados nessa relação. Parece, entretanto, que não é bem dessa maneira que ocorre. Vejamos:

“(...) é porque ele num ... porque home qué defendê o lado deles, e que a gente se vire, que a gente é que tem que defendê, eles num tá nem aí; eles acham que a gente tem que defendê, quando a gente falha, igual quando fiquei grávida desse aqui, ele falô tanto, aí eu falei: mas ocê podia ter usado camisinha".

A indicação de que o homem participa pouco da contracepção sinaliza que é preciso uma atenção renovada para o papel que o homem deve desempenhar em face do rápido desenvolvimento socioeconômico que está ocorrendo e das mudanças decorrentes desse desenvolvimento, exigindo uma nova concepção de participação masculina na vida reprodutiva e na privada.

A idéia de coexistência cremos ser o caminho mais apropriado e que possibilitará uma aproximação à essa nova concepção. É fundamental que na coexistência exista o espaço para compartilhar e não confrontar e cultivar os princípios de liberdade e cidadania da mulher.

\section{O seu ser mãe}

A situação explicitada nos depoimentos e a leitura que fizemos dos gestos e expressões ligada à emoção das mulheres revelam a carência de solidariedade do homem-pai, no sentido de compartilhar desta vivência tão forte e humana que é criar um ser humano. É difícil e pesado para a mãe arcar sozinha com a responsabilidade da educação dos filhos. $\mathrm{O}$ fato de as mães assumirem todas as tarefas ligadas ao âmbito da maternidade, do lar e das tarefas internas da família, produz um desgaste intenso, passando elas ainda, por muitas dificuldades para prover a prole das necessidades básicas como alimentação, vestuário e educação. Quando essas necessidades ficam ameaçadas elas demonstram temor de terem de abandonar os filhos e temor à marginalidade decorrentes do abandono, em face da falta de recursos materi- 
ais. Vejamos fragmentos de discurso que convergem para esse pensamento:

“(...) a gente mora na roça, em Santa Maria, e a gente que trabaia na roça.. a gente cria os fios da gente, ali a gente tem que capiná, buscá lenha, fazê né ... então prá gente criá, que eu já tive 8 ”.

“(...) meus menino, ele é sete, agora nenhum tem estudo ... só estudo até a quarta série, então eu aborreço com um trem desse né ... agora, a gente não podê dá um estudo po menino da gente é dureza ... vô pará por aí se Deus me ajudá, com a ajuda de Deus e docêis eu vô pará com isso".

As mudanças nos papéis sociais da mulher e a maneira como a sociedade os incorpora têm reflexos sobre o comportamento reprodutivo. Porém, se o papel da mulher é susceptível a mudanças, o mesmo não ocorre com o do homem. Esse tem permanecido intocável, cabendo à mulher viver num mundo de ambigüidades entre o doméstico e o público, com má distribuição das atividades no tempo e no espaço e com complexos problemas assumidos e vivenciados unicamente pelas mulheres, principalmente pelas mais pobres.

\section{A condição socioeconomica e o número de filhos}

Esse aspecto emergiu com bastante ênfase nos depoimentos. Apreendemos, através de expressões e sentimentos das mulheres, o peso atribuído à questão econômica. A necessidade de limitar o número de filhos é associada às dificuldades materiais de subsistência e ao desejo de oferecer melhor qualidade de vida aos filhos. Vejamos alguns fragmentos de discurso:

“(...) aí eu quero ligá mesmo, eu não tenho condição de cria tanto filho (...) porque 4 filho já é muito, é demais".

"(...) ocê nasce um menino. ocê não tem condições de dá a ele as coisas dele, alimentá direito né, come lá sempre um arroz um feijão, lá uma verdurinha ... é dificil da gente compra até carne pás criança cumê ".

As mulheres alegam e reforçam que um forte motivo que as impulsionou a tomar a decisão de não ter mais filhos são as limitações impostas pelas condições econômicas. A decisão de não ter mais filhos, na nossa maneira de ver, está relacionada a uma situação na qual as mulheres se encontram engajadas, que pesa nessa decisão. A escolha é a de nosso caráter inteiro e de nossa maneira de estar no mundo. A mulher é livre para escolher ter ou não ter filhos, porque a escolha é concreta, ela é feita ao longo de uma existência. Não obstante, encontra-se muitas vezes presa às amarras das instituições sociais, políticas, jurídicas, elas possuem uma força interior que as impulsiona na sua realização como ser humano. O desejo de ser mais do que ela é neste momento de sua existência, direciona-a para uma nova situação existencial. A liberdade existencial não é livre arbítrio, nem ela é dada, ela é conquistada por nós dentro de nossas possibilidades.

\section{O novo horizonte existencial em face da esterilização cirúrgica}

Através das falas das mulheres, desvelouse que o sentido de encerrar a vida reprodutiva, através da esterilização cirúrgica, permitirá às mulheres insinuar o seu devir. O seu novo horizonte apresenta-se cheio de possibilidades e as remete para seus projetos futuros, seu vir-a-ser. Podemos dizer que a esterilização parece estar ligada às transformações que vão se delineando na vida da mulher, e a cirurgia apresenta-se como um passo para novas conquistas.

Para MERLEAU-PONTY (1971) o corpo não é um objeto, como na concepção mecanicista, mas uma teia de funções ligadas à comunicação: visão, motricidade, sexualidade, emoção; campo fenomenal do sentir e do sensível. O corpo transforma-se no eixo fundamental para as conexões sentido-existência, que se manifestam em nível perceptivo.

Fundamentadas nesse autor podemos dizer que o corpo aparece para a mulher como uma posição em vista de uma certa tarefa atual, ou possível. O corpo é o poder que nós temos de nos mover, nos deslocar, permite-nos executar urna ação, expressar-nos e assim projetarmos as significações.

Pudemos apreender o sentido do corpo trabalhador, aquele que precisa desencumbir-se da tarefa da maternidade para entrar no mundo produtivo e assim contribuir para compor a renda familiar. Observemos as seguintes unidades de significado:

“(,..) eu pretendo ainda quando ele (o filho) tivé uns 3 meses, ainda trbalhá, né, se Deus quisé, prá podê ajudá em casa".

“(...) agora, eu vou trabalhá e ajudá ele, igual número de filhos, né, eu tenho suficiente. né".

Pudemos apreender o sentido do corpo culpado, aquele que teme ser penalizado com a morte, ao assumir, voluntariamente, encerrar sua vida reprodutiva - característica peculiar da mulher.

Às vezes o desejo de livrar-se de uma gravidez não desejada é tão forte que a mulher abre mão de sua sexualidade e enfrenta o fantasma da frigidez. Vejamos o seguinte fragmento de discurso: 
“(...) eu quero ligá; eles fala que ... muié ligada num ... num fica a gosto do marido, esfria muito, mas né ... fica fria. o marido vai paquerá otra, vai larga ela de lado; eu prefiro ficá só com meus fios só, do que ficá encheno a casa, depois quem vai sofre é a gente mesmo pá pode dá conta deles".

Pudemos apreender também o sentido do corpo sexuado, na medida em que a mulher compreende a esterilização como uma possibilidade de elimimar a insegurança de uma gestação indesejada, em direção a uma vida sexual melhor. Vejamos:

“(...) não preciso preocupá de todo mes ficá comprano remédio, posso levá minha vida normal ... não precisa ficá tomano comprimido todo dia, levá uma vida tranqüila, porque se a gente não tá tomano remédio, a gente não sente nem prazer direito, né, porque a gente fica com aquela cabeça, pensano que vai engravidá".

Separar o prazer da reprodução é apenas um passo para uma vivência sexual com mais qualidade, entretanto, a complexidade das relações humanas e, em especial da vida sexual, não se resolveriam só por uma contracepção eficaz.

Os movimentos de nosso corpo devem buscar a razão de ser de nossa existência. E o existir é estar em constante processo, indo em busca de algo, sempre adiante, caminhando para um futuro que se oferece a nós para ser conquistado com possibilidades projetadas.

\section{Refletindo sobre o estudo}

A compreensão do fenômeno de decisão pela esterilização cirúrgica, foi buscada por nós a partir da estrutura do mesmo, sem a pretensão de oferecer explicações para problemas, mas sim, apresentar a nossa reflexão e interpretação como enfermeiras sanitaristas e mulheres.

Durante a elaboração deste estudo foi-se construindo uma nova perspectiva do cotidiano das mulheres que buscavam algum meio para regulação da fecundidade do casal. Dessa maneira, a compreensão do significado da escolha da esterilização cirúrgica feminina emergiu da fala das mulheres que vivenciaram essa experiência, através desse compreender, acreditamos que os profissionais de saúde poderão criar novas possibilidades para um assistir numa dimensão humana.

Da análise das proposições resultantes dos depoimentos, pudemos apreender um caminhar lento e quase inevitável para a esterilização cirúrgica. No inicio da vida reprodutiva essas mulheres usaram métodos contraceptivos temporários, muito embora esse uso estivesse extremamente limitado pelo acesso insuficiente aos métodos anticoncepcionais.

Ao longo de sua vida reprodutiva, a mulher, já experiente com os métodos temporários, começa a cotejá-los com o método definitivo esterilização cirúrgica e conclui que ele é mais eficaz porque ela decidiu não ter mais filhos, libertando-se das amarras da maternidade, para vislumbrar um novo devir e decidir por vários caminhos enquanto ser de possibilidades. Esse ser de possibilidades emerge de um mundo onde se delineiam suas condições históricas de existência.

Foi possível compreender o processso de escolha do método definitivo a partir dos aspectos essenciais do fenômeno, que estão relacionados à maneira como as mulheres percebem 0 mundo e com ele se relacionam. O esgotamento de possibilidades com os meios contraceptivos temporários, no decorrer de sua vida reprodutiva, associado ao falo de não querer mais filhos é um processo que conduz a mulher a escolher o método definitivo. Essa escolha está permeada de ambiguidades. Se, por um lado, essa escolha a liberta de uma gravidez indesejada, deixa por outro, transparecer um sentimento de culpa por ter assumido, voluntariamente, encerrar sua vida reprodutiva.

Como já sabemos, as estatísticas nos alertam para o alarmante número de mulheres brasileiras que adotam essa maneira radical de eliminar a possibilidade de uma nova gravidez, a um custo psicológico altísssimo. Essa escolha foi sendo, de certa maneira, imposta às mulheres ao longo de suas vidas reprodutivas, como única opção, que seguramente, elimina o temor de uma nova gravidez. Ao nosso ver o caráter de necessidade que a esterilização ocupa entre as mulheres, ocorre, muitas vezes, pela falta de opção de controlar falhas decorrentes do uso de métodos contraceptivos temporários.

A condição socioeconômica e o mimero ele filhos, assim como o ser mãe são facetas relevantes, pois, em nossa compreensão anunciam transformações sutis, porém, extremamente importantes. Nesse sentido MURARO (1992) permite-nos esclarecer que a adequação da mulher para o privado e do homem para o público é concretizado na própria identificação sexual de ambos. O homem torna-se egoísta, competitivo e agressivo, e a mulher altruísta, pois foi preparada para a partilha, a solidariedade e o amor com definição de sua própria identificação feminina.

Agora, contudo, entramos no mundo masculino e temos uma dupla jornada de trabalho (doméstico e produtivo), justamente por causa desse caráter egoísta do homem e altruísta da mulher. O que podemos perceber através deste estudo, é que 
essas mulheres, nestas condições, estão questionando e solicitando a participação do homem na vida privada (doméstica). Segundo constatação de MURARO (1992), tal fenômeno, mais genericamente observado, vem trazendo uma transformação das estruturas psíquicas, tanto de homens quanto das mulheres e, concomitantemente, uma mudança nas estruturas socioeconômicas pelos caminhos mais surpreendestes. Na medida em que a mulher entra para o domínio do público, o homem vê-se obrigado a entrar para o domínio do privado, ajudando a companheira nos trabalhos domésticos e no cuidado com os filhos. Esta simples mudança traz conseqüências profundas.

A mesma autora menciona ainda que neste limiar do Terceiro Milênio está acontecendo uma revolução fantástica. pelo fato de o capitalismo ter fabricado mais máquinas do que machos, as mulheres invadem o mundo masculino e, tecnicamente, acabam com a separação entre o mundo privado e o público. Podemos, assim, falar em um embrião de superação do patriarcado, ao mesmo tempo em que trazemos para o domínio público valores de que somos tão profundamente portadoras, ou seja, de solidariedade e partilha, que podem nos salvar da destruição da competitividade.

A complexidade da questão exige que a vejamos por vários ângulos, entretanto esse estudo permitiu captar determinada perspectiva, sem a pretensão de esgotá-lo. Em um primeiro momento é preciso tornar acessível às mulheres todos os métodos atualmente disponíveis, principalmente através de programas educativos que forneçam não apenas informações, mas que trabalhem na formação de novas atitudes em relação aos métodos naturais ou comportamentais, criando condições para mostrar sua eficácia quando usados corretamente.

É preciso, também, que se atenda a uma preocupação fundamental das mulheres - a eficácia de métodos. Para tanto, é necessário desenvolver pesquisas no sentido de serem descobertos métodos que atendam, também, a principios como facilidade de uso, de acesso - tanto econômico quanto cultural - e de reversibilidade.

Os homens devem também ser o enfoque dos programas de planejamento familiar, a fim de estimular o seu envolvimento e participação. Os programas pressupõem, freqüentemente, que o planejamento familiar é uma questão feminina, quando esses serviços se combinam, com os serviços de saúde materno-infantil. Abordar o planejamento familiar a partir da concepção do exercício da sexualidade humana, onde feminino e masculino tenham lugar, seja talvez uma maneira de ampliarmos sua concepção, sem no entanto, desvinculá-lo do contexto da saúde.
O planejamento familiar permite que o homem seja o agente de seu processo reprodutivo e realize uma de suas potencialidades, que é a sexualidade. Como tudo o que é humano, a sexualidade possui outras dimensões que não são exclusivamente biológicas . O exercício da sexualidade é uma forma de comunicação existencial, o lugar próprio da afetividade e não apenas um lugar para a reprodução da espécie. A prática sexual, portanto, deixa de ser somente a satisfação de uma necessidade biológica para tornar-se um exercicio do espirito humano. Como diz MerleauPonty: "se a história sexual do homen dá a chave de sua vida, é porque na sexualidade do homem se projeta sua maneira de ser com relação ao mundo, isto é, com o tempo e aos outros homens." (MRLEAU-PONTY, 1971).

Este estudo possibilitou-nos compreender a importância de repensar a assistência de enfermagem às mulheres que procuram um meio para regular a sua fertilidade, tendo como eixo o ser humano que tem vida histórica e familiar. Tratar a problemática da esterilização cirúrgica feminina da perspectiva biologicista oculta dimensões significativas da vida das mulheres, dificultando, assim, uma abordagem que nos permita transcender a atual problemática.

A prática da assistência a esse grupo de mulheres, ao concentrar-se no corpo biológico, revela uma atenção massificada, coisificada, impossibilitando compreender o outro numa dimensão existencial. Essa visão dos serviços de saúde, que exclui a mulher das decisões tomadas sobre seu corpo e a sua maternidade, funciona como força de opressão, contribuíndo para fixar os papéis e as opções desta. Esse estudo abre perspectivas para uma nova prática na assistência de enfermagem, que contemple a totalidade do homem e não apenas o seu aspecto biológico, orgânico. Neste sentido, é também preciso repensar a formação dos profissionais de enfermagem; calcada no modelo das ciências naturais, enfatiza a individualidade biológica do ser humano, retirando-lhe a possibilidade de expressar-se em toda a sua plenitude.

Este estudo, ao mesmo tempo que permitiu ampliar o horizonte de compreensão do processo de decisão pela esterilização cirúrgica, abriu pistas para novas necessidades de aprofundamento.

Neste sentido consideramos importante destacar a necessidade de se aprofundar a temática relacionada ao significado atribuído ao corpo, pela mulher que escolhe a esterilização cirúrgica. Se nosso corpo é nosso veículo do ser-no-mundo projetamos, então, nele nossa maneira de estarno-mundo, daí ser possível interrogar que significado as mulheres que escolhem a esterilização atribuem aos corpos; a que servem esses corpos, que 
lugar, no seu amplo mundo de significações, lhe reserva.

Essa questão mobiliza-nos para um aprofundamento do tema, a fim de especificar e de qualificar, com mais precisão, a interrogação que a partir de agora passa a desafiar-nos.

\section{BIBLIOGRAFIA}

BEMFAM. Pesquisa nacional sobre saúde maternoinfantil e planejamento familiar. Rio de Janeiro, 1986.

CAPALBO, C. Alternativas metodológicas de pesquisa. In: Seminário Nacional de Pesquisa em Enfermagem, 3º, Florianópolis, 1984. Anais, Florianópolis, Universidade Federal de Santa Catarina, 1984. p. 130-55.

MARCOLINO, C. Trajetória da mulher em direção à esterilização cirúrgica feminina: um estudo fenomenológico. São Paulo, 1994. [Dissertação de Mestrado - Faculdade de Saúde Pública da USP].

MARTINS, J.; BICUDO, M. A. V. Estudos sobre existencialismo, fenomenologia e educação. São Paulo, Moraes, 1983.

\section{AGRADECIMENTOS}

À Dra. Magali Roseira Boemer - Professor Livre - docente da Escola de Enfermagem de Ribeirão Preto/USP, pelo assessoramento prestado a este estudo.

MARTINS, J.; BICUDO, M. A. V. A pesquisa qualita^hva em psicologia: recursos e fundamentos básicos. São Paulo, EDUC - Editora da PUC-SP, 1989.

MERLEAU-PONTY, M. Fenomenologia da percepção. São Paulo, Freitas Bastos, 1971.

MURARO, R. M. A mulher no terceiro milênio: uma história da mulher através dos tempos e suas perspectivas para o futuro. Rio de Janeiro, Rosa dos Tempos, 1992.

SERRUYA, S. Ligação de trompas e imaginário feminino. In: Encontro Nacional de Estudos Populacionais, $8^{\circ}$, São Paulo, 1992. Anais. São Paulo, Associação Brasileira de Estudos Populacionais, 1992. p. 43-59.

recebido: 31/07/95 aprovado: 30/10/95 